\title{
Rhodium(I) 2-hydroxypyridine N-oxide (hopo) complexes: synthesis, characterization and reactions
}

Mohammed Elmakki, Department of Chemistry, Omdurman Islamic University, Khartoum, Sudan. Gertruida J.S. Venter*, Department of Chemistry, University of the Free State, Bloemfontein, South Africa.

Johan A. Venter, Department of Chemistry, University of the Free State, Bloemfontein, South Africa. *E-mail:VenterGJS@ufs.ac.za

There are several essential reactions with regard to homogeneous catalysis that transition metal complexes can undergo, such as oxidative addition, insertion, substitution and reductive elimination. A key to understand catalytic processes requires research on homogeneous catalysis and the relationships between activity and catalyst structure. Oxidative addition is one type of reaction that can very often be identified in the mechanistic scheme of catalytic processes.

The electronic and steric modifications to tertiary phosphines, often used as ancillary ligands, can lead to more effective modelling of catalysts. These phosphine ligands are exceptionally well suited to manipulate the electron density and / or steric accessibility of the metal centre. In this study, the oxidative addition of $\left[\mathrm{Rh}(\right.$ hopo $\left.)(\mathrm{CO})\left(\mathrm{PX}_{3}\right)\right]$ (where $\mathrm{PX}_{3}=\mathrm{PCy}, \mathrm{P}(\mathrm{o}-\mathrm{Tol})_{3}, \mathrm{PPh}_{3}$, $\mathrm{PPh}_{2} \mathrm{C}_{6} \mathrm{~F}_{5}, \mathrm{P}\left(\mathrm{p}-\mathrm{ClC}_{6} \mathrm{H}_{4}\right)_{3}, \mathrm{P}\left(\mathrm{p}-\mathrm{MeOC}_{6} \mathrm{H}_{4}\right)_{3}$ and hopoH is 2-hydroxypyridine $N$-oxide) with iodomethane to give $\mathrm{Rh}$ (III) alkyl complexes were studied in a range of different solvents in an attempt to separate and quantify the steric and electronic effects of the phosphine ligand. These complexes were synthesized, studied by IR, NMR and X-ray crystallography and will be discussed in this presentation.

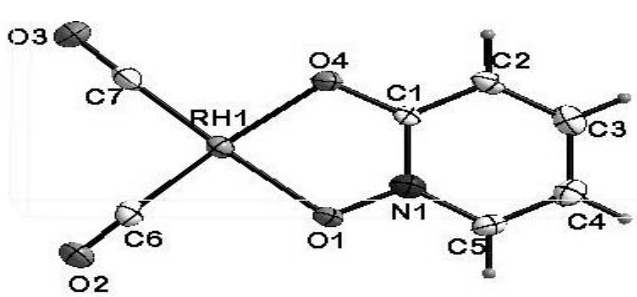

(a)

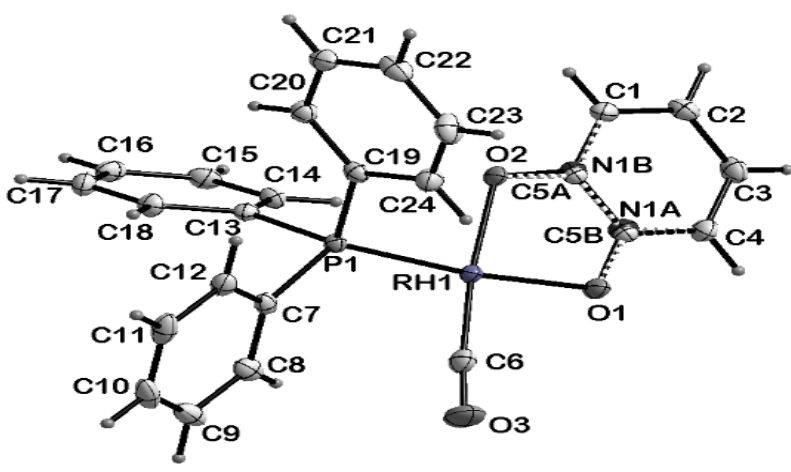

(b)

Figure 1: Schematic presentations of (a) Dicarbonyl(pyridin-2-olate-1-oxido- $\left.\kappa^{2} O, O^{\prime}\right)$ rhodium(I) and, (b) Carbonyl(2-oxopyridin-1(2H)-olato- $\left.\kappa^{2} O, O^{\prime}\right)$ (triphenylphosphine$\kappa P)$ rhodium(I). 